\title{
Cross sectional Study to look at the factors leading to therapeutic inertia in UK primary setting in the management of T2DM
}

\section{Azhar Zafar ${ }^{1,2}$, Nihad Jalili ${ }^{3}$, Arslan Saleem ${ }^{5}$, Kamlesh Khunti ${ }^{1,4}$.}

1. Leicester Diabetes Centre, UK, 2. GP Alliance Federation Northampton 3. Consultant Endocrinologist Northampton General Hospital 4. Department of Basic Health Sciences, University of Leicester, UK 5. Hameed Latif Memorial Hospital Lahore, Pakistan

\section{Background:}

Current literature has provided evidence that recommended control of $\mathrm{HbA1c}$, blood pressure, and dyslipidemia reduces the risk of developing diabetes-related macro- and microvascular complications and cardiovascular death'. Literature presented different factors including clinical inertia, responsible for these management gaps. Clinical inertia is defined as failure to intensify therapy when indicated ${ }^{2}$. Reasons for clinical inertia are multi-factorial ${ }^{3-4}$. Current literature cannot demonstrate documented factors leading to clinical inertia in the care of persons living with T2DM in the UK primary care setting ${ }^{5}$.

\section{Aim}

To study factors associated with therapeutic inertia in the management of T2DM in UK primary setting and to develop a predictor model to estimate the probability of therapeutic inertia based on patient factors, clinical characteristics, and level of care provided.

\section{Method}

Multicentre, observational, cross-sectional study where each participating clinician collected clinical data on consecutive patient's consultations. An event of Therapeutic inertia was defined as a consultation in which treatment change was indicated (i.e. $\mathrm{HbA} 1 \mathrm{c}>58 \mathrm{mmol} / \mathrm{mol}$ ) in all patients but did not occur. The predictive factors were analysed and the association of factors with inertia were validated.

\section{Results}

Data were collected on 128 patient consultations. The binary logistic regression model showed that odds of therapeutic inertia were 1.10 with the increasing age, 38.3 with $\mathrm{A} 1 \mathrm{C}$ levels of $58-65 \mathrm{mmol} / \mathrm{mol}$ as compared to higher $\mathrm{HbA} 1 \mathrm{c}$ levels, odds of 6.3 with $66-75 \mathrm{mmol} / \mathrm{mol}$ than other A1C levels. Similarly, odds of therapeutic inertia in higher systolic BP $(>140)$ were 1.1.

The linear regression model predicted $(p<0.001)$ that therapeutic inertia occurred 15.1 times more with lower $A 1 \mathrm{c}$ as compared to higher A1c (B coefficient 86.57). Other predictors of therapeutic inertia in consultations included the competing demands of other presenting problems when consulted by GP as compared to a PN $(p<0.001)$ and patients based factors for clinical inertia.

\section{Conclusion}

Although therapeutic inertia is frequent in the management of T2DM, the factors explaining it are not completely clear. Whereas some aspects of the consultations were associated with therapeutic inertia, patients related factors were not the only decisive factor leading to clinical inertia.

\section{References}

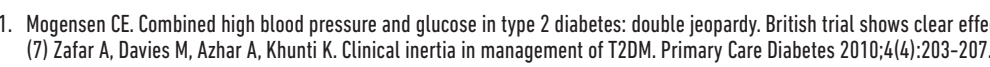

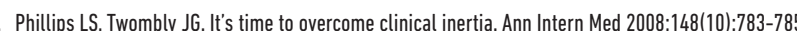

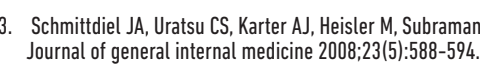

4. Zafar A, Stone $M$, Davies $M$, Khunti K. Acknowledging and allocitint

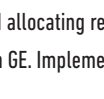

Therapeutic inertia is statistically significantly associated with the HbA1c level ( $p$-value $<0.001$ )

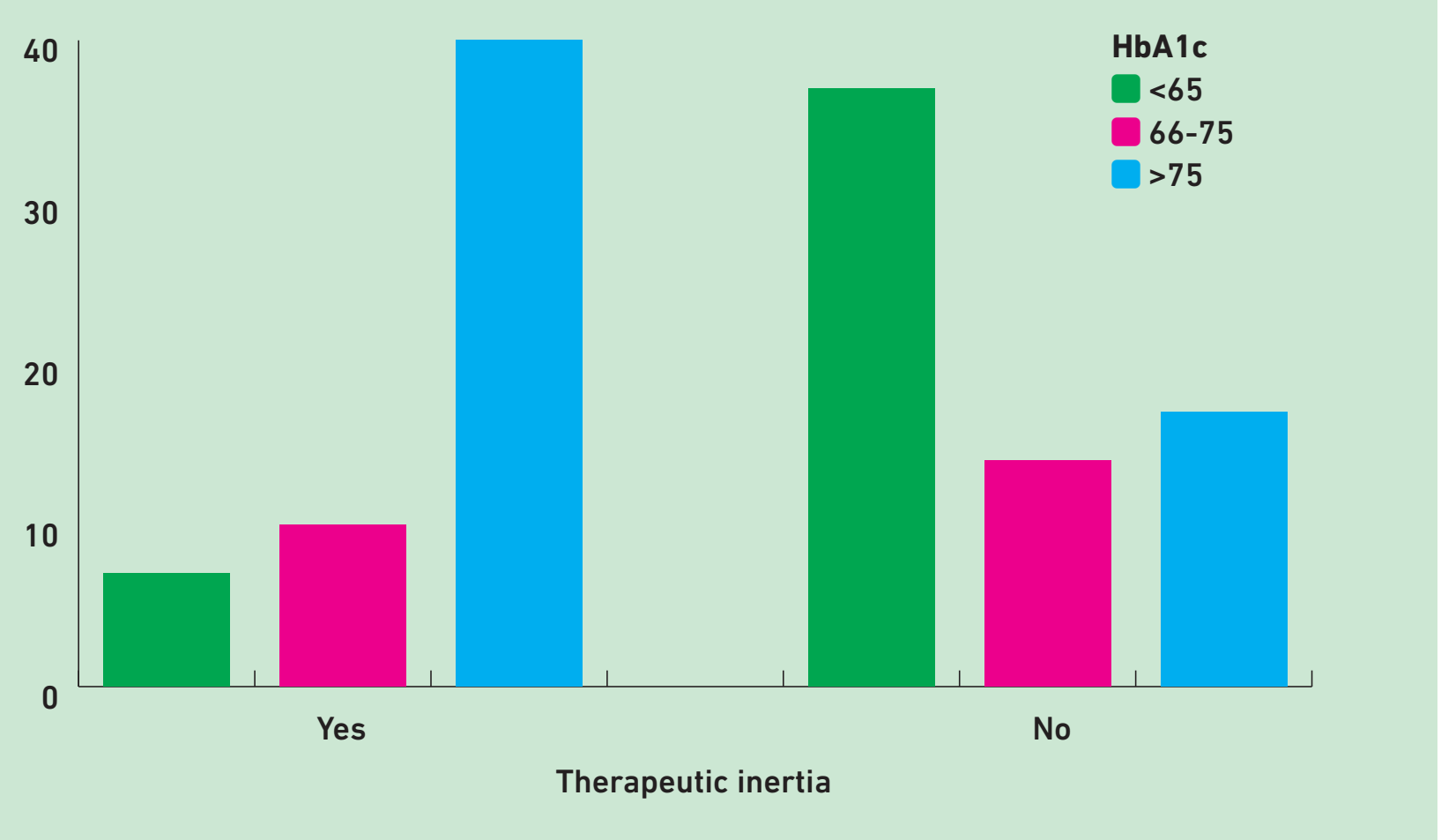

Variation explained are $35.4 \%$

There is 0.441 times less chances of intensification of drug when consulted by GP.

With the unit increase in $\mathrm{HbA} 1 \mathrm{c}$ level there is 0.009 times more likely chance of intensification of drug

Block 1: Method = Forward Stepwise (Conditional)

\begin{tabular}{l|l|l|l|l|l|l|l}
\multicolumn{2}{l}{ Variables in the Equation } & \multicolumn{7}{l}{$l$} & \\
\hline & & B & S.E. & Wald & df & Sig. & Exp(B) \\
\hline Step 1 & A1C & -0.068 & 0.016 & 18.352 & 1 & 0 & 0.934 \\
\hline & Constant & 5.445 & 1.223 & 19.817 & 1 & 0 & 231.625 \\
\hline Step 1 $^{\text {b }}$ & A1C & -0.064 & 0.016 & 15.206 & 1 & 0 & 0.938 \\
\hline & DBP & 0.06 & 0.027 & 4.923 & 1 & 0.026 & 1.062 \\
\hline & Constant & 0.406 & 2.49 & 0.027 & 1 & 0.871 & 1.5 \\
\hline
\end{tabular}

a. Variable(s) entered on step 1: A1C.

b. Variable(s) entered on step 2: DBP.

\begin{tabular}{|c|c|c|c|c|c|c|}
\hline \multicolumn{7}{|c|}{ Coefficients } \\
\hline \multicolumn{2}{|c|}{ Model } & \multicolumn{2}{|c|}{$\begin{array}{l}\text { Unstandardized } \\
\text { Coefficients }\end{array}$} & \multirow[t]{2}{*}{$\begin{array}{l}\text { Standardized } \\
\text { Coefficients }\end{array}$} & \multirow{2}{*}{$\begin{array}{l}\text { t } \\
11.717\end{array}$} & \multirow{2}{*}{$\begin{array}{l}\text { Sig } \\
.000\end{array}$} \\
\hline 1 & (Constant) & .762 & .065 & & & \\
\hline & FU_GP_PN & -.548 & .086 & -.545 & -6.366 & .000 \\
\hline \multirow[t]{3}{*}{2} & (Constant) & .013 & .239 & & .054 & .957 \\
\hline & FU_GP_PN & -.441 & .088 & -.438 & -4.984 & .000 \\
\hline & HbA1c level & .009 & .003 & .286 & 3.249 & .002 \\
\hline
\end{tabular}

